\title{
Study on New Rural Ecological Environment Construction and Sustainable Economic Development in Hainan
}

\author{
Hong Suo, Xiaojun Gan \\ College of economics and management, Hainan Normal University, Haikou, Hainan, 571158, China
}

\begin{abstract}
Keywords: Hainan, Socialism New Rural Construction, Ecological Environment, Sustainable
\end{abstract} Economic Development

\begin{abstract}
As Chinese socialism new rural construction policy is carried out in Hainan, Hainan rural economic construction achieves rapid development. However, when rural ecological environment has been fully developed and used, there are still so many environmental problems. Only by promoting ecological protection can the sustainable development of rural economy be carried forward. Hainan Province on the one hand carries out rural ecological environment construction and on the other hand takes "seeking development with protection" as guiding thought, which isn't truly practicable in actual operation. Main reasons lie in insufficient capital investment for ecological environment construction, unreasonable rural economic structure of Hainan, etc. This paper conducts a study on new rural ecological environment construction in Hainan and existing problems in sustainable economic development.
\end{abstract}

\section{Introduction}

Since 1996, Hainan has put forward “One Province Two Places” development strategy on basis of building favorable ecological environment, which is vital for the development of entire Hainan Province. It is also an active exploration of Hainan ecological development to integrate Hainan agriculture, tourism and infant industry together. In 1999, Hainan Province put forward "ecosystem-friendly province", becoming the first ecological environment construction demonstration province in China through state approval. Since the year of 2000, Hainan Province took rural area as carrier in socialism new rural construction, started civilized and ecological village construction and made "ecosystem-friendly province" firstly carried out in Hainan rural areas. Up to 2011, a year after the starting of civilized and ecological village construction, more than half of the natural villages in Hainan Province have been turned into civilized and ecological villages. Various social and economic development indicators have been improved to a new level. Rural areas started road works; water and power supply has been improved; communication network has been established in Hainan rural areas; all aspects like medical treatment and public health, educational culture, social insurance, etc have all achieved breakthrough. Since the national requirement for ecological environment construction has been shifted from behavior practice to theoretical height, ecological environment is no longer confined to specific ecological behavior but asking for building ecological civilization concept. The environmental law should be reinforced when constructing ecological civilization. Then rural ecological environment construction should also be carried out in environmental legal construction in order to propose significant guiding ideas for the new rural development in Hainan. For so many years, Hainan has kept the way of "ecosystem-friendly province”. Hainan new rural ecological environment construction has achieved brand strategy especially in aspect of rural ecological construction. It perfects Hainan urbanization development, improves the rural economic development, ensures higher agricultural economy benefit for rural areas, and achieves Hainan new rural areas' goal of building a rural society in an all-round way.

\section{Relationship between Hainan rural environmental protection and economic development}

Hainan Province puts forward "ecosystem-friendly province”, highlighting the advantages of rural ecological development. China socialism new rural construction aims to promote the development of agricultural economy and improve the living standard of rural residents. As new rural ecological environment construction unfolds, Hainan puts forward that the characteristics and 
advantages of Hainan should be fully used with the pace of socialism new rural construction. Rural areas should be taken as carrier in rural economic development in order to set up brand strategy of ecological environmental protection. With the gradually increasing of people's ecological environmental protection awareness, not only environmental ecologicalization but also ecological concepts should be permeated into all aspects of daily life. However, due to the poor agricultural production ability of Hainan, rural ecological environment doesn't suffer from serious destruction, which in turn highlights the advantages of Hainan rural ecological development. Since building special area, Hainan Province sets up its own agricultural economy development way. In addition, Hainan rural areas still remain original ecological environment, attracting more and more development projects. With the rapid development of agricultural economy, all kinds of chemical pesticide have been used in agricultural planting in order to meet the rapid development of local agriculture. However, the usage of these chemical pesticides causes serious environmental pollution especially in Hainan area where marine aquaculture takes the leading role. Serious water pollution brings about giant loss for Hainan aquaculture. The agricultural environment problems in Hainan Province greatly hinder sustainable economic development in Hainan.

Hainan improves agricultural development with help of agricultural environmental protection. The development of Chinese tourism economy provides positioning for Hainan tourism construction. Hainan Province as a modern agriculture demonstration base can promote the development of tourism only by taking an agroecological environment construction route. Environmental protection has become the precondition of Hainan agricultural development. The relationship between economic development and ecological environmental protection has received wide attention. It can be analyzed from perspective of sociology that protection and development are likely to facilitate and improve each other. In order to realize sustainable economic development in Hainan, great attention should be paid to ecological environmental protection which is taken as the supporting point. At the same time, agriculture should be considered as a carrier to seek development in protection and promote ecological environmental protection in development.

Hainan possesses advantaged ecological environment. Especially Hainan civilized and ecological village construction in recent years has improved the development of non-pollution agriculture. Hainan also possesses favorable agroecological environment which acts as the basic economic guarantee and environmental guarantee of rural economic development. If taking the win-win route of development and protection, Hainan should gain more economic benefit by paying less ecological environment price, and create social benefit and ecological benefit when improving economic benefit.

\section{Basic information of Hainan rural ecological construction}

Hainan Province carries out civilized and ecological village construction activities in order to make a full play of rural land source in Hainan, which not only develops garden economy but also promotes surrounding village greening. It brings significant achievement to Hainan rural ecological environment construction and certain economic benefit to villagers. Starting from perspective of policies, with various preferential policies of socialism new rural construction being carried out in Hainan rural areas, Hainan rural areas have realized urbanization development. Biogas digester construction is popularized in Hainan rural areas and the roads inside and outside of villages have all been reconstructed and installed with street lamps. "Three reforms"-water reform, toilet reform and pen reform and sufficient greening has been realized. The health environment is also improved. With the reconstruction of villages, some civil houses have been rebuilt. Taking Daben Village in Xiangshi Town, Baoting County, Hainan Province as an example, more than 8 million Yuan has been invested between 2010 and 2014 to build 30 mixing construction houses. There are more than 60 houses in total, covering 3600 square meters.

As new rural ecological environment construction in Hainan quickens its pace, ecological environment construction isn't confined to ecological greening and environmental management any more. In turn, ecological construction has been pushed forward to spiritual level which means paying more attention to Hainan rural ecological culture construction. The improvement of farmers' 
comprehensive quality has become an essential condition in Hainan new rural ecological environment construction. So far, Hainan Province brings the measure of improving farmers' comprehensive quality into ecological environment construction in order to promote their civilization level and ecological protection awareness ${ }^{[3]}$. The ecological civilization education for farmers in Hainan Province unfolds in various ways and mainly aims to shape civilization education environment like culture propaganda column, reading room, basketball court, etc. In addition, from the perspective of respecting national minority, activities with national features are also carried out. While receiving education, villagers not only know some national policies and guidelines but also realize the importance of making a fortune on basis of scientific agriculture. With the improvement of villagers' self-study awareness, they will take an active part in construction of ecological agriculture so that the sustainable development of Hainan new rural ecological environment construction can be improved.

\section{Existing problems of Hainan new rural ecological environment construction and rural economic development}

Insufficient capital investment in ecological environment construction. In Hainan ecological environment construction, the government will allocate partial funding from finance for Hainan ecological construction. However, units' subvention and villages' self-raised funding is still the main channel. For example, Hainan Province has allocated 6 million Yuan for rural ecological environment construction during 2009 and 2012. In 2012, with the implementation of Hainan ecological environment funding, the construction funding invested by all sectors of society has been over 20 million Yuan. Villagers invest amount of capital which takes more than half of the capital investment. It is thus clear that financial fund is still insufficient in new rural ecological construction. In new rural environment construction, Hainan Province is just at the construction stage. More funds should be invested for promoting the follow-up development. However, rural economic power is limited. Once the capital investment is cut, Hainan new rural ecological construction will also be cut. It is rather adverse to the sustainable economic development in Hainan Province. New rural ecological environment construction is a systematic engineering which needs certain capital investment to perfect construction in various aspects. Rural ecological environment construction in Hainan just begins to take shape. If the capital management is not ready with regulation protection, it is hard to promote further development of new rural ecological environment construction.

Unreasonable rural economic structure in Hainan. With the development of Hainan tourist economy, serious consumption of natural resources makes the ecological environment in Hainan rather worrying. Hainan belonged to the desolate areas in the south in history which was separated from desolate areas in the south. The ecological environment there was very fragile and the economic development was rather behindhand. As a result, the cultural communication between this island and the mainland was extremely poor. The reform and opening-up policy facilitated the development of Hainan Province. However, due to unreasonable resource development, the natural resources in this area have been overly consumed, causing ecological environment deterioration. Main reasons are as follows. Even though rural ecological environment construction has been carried out in Hainan rural areas, the economic structure wasn't adjusted in accordance with Hainan economic development condition. Insufficient capital investment causes relatively slow infrastructure construction in Hainan Province and outdated ecological civilization. Roads and water conservancy facilities are the most important hardware facilities for rural development. If the infrastructure construction cannot keep pace with the economic development in Hainan Province, agricultural economy loss will be caused by environmental impacts ${ }^{[4]}$. For example, typhoon and rainstorm occasionally happen in rainy season of Hainan. If the infrastructure construction is adverse, roads as well as farmland will be damaged. If ecological forests in Hainan rural areas are damaged, ecological environment and the sustainable economic development in Hainan will definitely be influenced. 


\section{Countermeasures for Hainan new rural ecological environment construction and sustainable economic development}

Strengthen new rural ecological environment construction in Hainan. Some researchers put forward that Hainan new rural construction can be carried out smoothly and set solid foundation for new rural construction as long as rural "Green Brand" has been created and ecological construction of Hainan rural areas has been paid great attention to. At present, Hainan mainly focuses on tourist economy development. Ecological agricultural construction can be connected with Hainan tourism development to advocate ecological environment protection through agricultural tourist economy development. In this way can single agriculture green brand construction can be turned to comprehensive brand, making rural ecological construction Hainan's special brand ${ }^{[5]}$. At this stage, Hainan should create its own special brand, start from Hainan's actual situation, dig out recyclable resources, and improve resources' available value from perspective of culture. Therefore, the nation and related departments in Hainan Province should strengthen investment for new rural ecological environment construction, integrating government investment, enterprise investment and private investment together. In addition, enterprise investment is the most important. Hainan enterprises should increase their investment for rural ecological environment, make full use of marketing environment in Hainan areas, develop product market, and improve sustainable economic development. With more and more capital investment for rural ecological environment, rural infrastructure will be constantly perfected, playing a vital role in rural sustainable economic development.

Improve Hainan rural economic structure. Hainan Island is honored as "Four-season Ecological Garden Island” in China, where the advantaged ecological environment has become an anchor point for Hainan agricultural development. Hainan which was once poor develops itself with help of the reform and opening-up policy, making this island a charming scenery in south of China. With the development of China socialism new rural construction and also ecological environmental protection, Hainan new rural ecological environment construction has become the basic condition for economic development. Taking strategy of sustainable development into Hainan new rural ecological environment construction to develop circular economy and promote cleaning development of agricultural economy has maximized the resource utilization of Hainan rural areas. Recycling economy is able to improve circular using of resource, guiding villagers' energy conservation awareness. Therefore, new rural ecological environment construction means not only ecological behavior but also improvement of ecology awareness. What we should do is to improve Hainan villagers' understanding of ecological construction, facilitate the development of Hainan service industry, and strengthen brand construction. Ecological environment construction forms unconscious education for villagers. The constant expanding of service industry drives the development of Hainan rural ecological economy.

\section{Conclusion}

In conclusion, China socialism new rural construction has entered a new developing phase. Hainan new rural ecological environment construction also meets its golden opportunity period. Compared with other districts in China, Hainan takes the lead in development since China's reforms and open policy and plays a leading role in rural ecological environment construction. However, it can be seen from construction planning that staying in exploration phase for many years will cause tortuous path in Hainan rural ecological environment construction. In order to make Hainan new rural ecological environment construction keep pace with urbanization development, rural economic ability should be improved to promote the sustainable development of Hainan rural ecological environment. 


\section{Acknowledgments}

This subject title is Research on Marxism View of Nature and Socialism New Rural Environment Construction in Hainan. No.: HNKY2014-45

\section{References}

[1] Wu Xiaolin. Existing problems and countermeasures of civilized and ecological village construction in Hainan. Journal of Hainan Normal University (Social Science Edition), 2014,27(02):76-81.

[2] Chen Gang, Chen Guiming. Zhigong Party Hainan Provincial Party Committee's advice on carrying forward national eco-compensation pilot province construction and assisting Hainan scientific development and green rising. 2013.

[3] Sun Tao, Wang Xi. Countermeasure study on the harmonious development of Hainan urbanization and ecological civilization. Science and Technology Innovation Herald, 2015(02):108-109.

[4] Yang Bangjie, Huang Junsheng, Chen Guiming, Shen Xiaoying. Investigation and analysis on Hainan rural ecological construction. China Development, 2014,14(05):1-8.

[5] Shi Tina. Study on expanding tourism function of civilized and ecological village, 2010

Contemporary Hainan Forum Collected Works (Volume 1).Haikou: Nanhai Publishing Company,2011:153-159. 